\title{
Appetite suppressing phyto nutrients: potential for combating obesity
}

\begin{abstract}
An appetite suppressant can be an excellent tool in weight management if used safely and effectively. There are some medicinal plants that have been reported to be acting as appetite suppressors or appetite killers. Some of these plants are Caralluma Fimbriata, Hoodia Gordonii, Camellia sinensis (Green Tea), Capsicum annuum(Sweet/Bell Pepper), Plantago ovata (Psyllium/Plantain Fiber), Saffron Extract, XanoLean, Flaxseeds, Ginger, Umeboshi Plums, Prunus dulcis (Almonds), Ilex paraguariensis(Yerba Mate) and Garcinia Cambogia, Aloe vera, Bee Pollen and Evening Primrose Oil. These types of herbal plants/ supplements can be especially useful for people suffering from obesity for their weight management. Obesity increases risk of diseases and health problems, such as heart disease, diabetes and high blood pressure. This paper therefore aims to explore and provide an insight about the medicinal plants with appetite suppressing activity.
\end{abstract}

Volume 3 Issue 3 - 2015

\author{
Charu Gupta,' Dhan Prakash,' Sneh Gupta² \\ 'Amity University UP, India \\ ${ }^{2}$ Department of Zoology, R.G.P.G. College, India
}

Correspondence: Charu Gupta, Amity Institute for Herbal Research \& Studies, Amity University UP, Sector-125, Noida-2013।3, India, Email charumicro@gmail.com

Received: October 27, 2015 | Published: December 22, 2015

Keywords: appetite, obesity, weight control, medicinal plants, appetite-suppressor, diseases

\section{Introduction}

The obesity statistics as per WHO depicts that the disease has doubled betweenyears 1980 and 2014. In a survey (2013), it was found that around 42 million children below the age of 5 were suffering from obesity. Obesity was once considered to be problem of developed or the high-income countries but is also now quite common in developing countries including middle-and low-income countries. The statistics of the reports indicate that these figures of childhood overweight and obesity are even $30 \%$ higher than that of the developed countries. In year 2014 alone, more than 1.9billion adults were overweight and out of these over 600 million people were suffering from obesity. Data has also shown that majority of the world's population is killed more due to obesity as compared to underweight or under-nutrition. ${ }^{1}$ This statistics is quite alarming.

Obesity is a significant risk factor for major diseases including type II diabetes, coronary heart disease, hypertension and certain forms of cancer. ${ }^{2}$ Obesity arises when energy intake, principally stored as triglycerides, exceeds energy expenditure. ${ }^{3}$ Obesity is a complex trait influenced by diet, developmental stage, age, physical activity and genes. ${ }^{4}$

However, overweight and obesity and their related noncommunicable diseases can be prevented by following a healthy lifestyle. The healthier food choices of an individual depend on the number of factors including ones surroundings, environment, lifestyle and physical activities etc. and indirectly affect the tendency to gain weight and obesity.

At an individual level, people can limit energy intake from total fats and sugars; they should increase the intake of fresh and seasonal fruit and vegetables, legumes, whole grains and nuts; and should follow a strict and regular physical regime. ${ }^{2}$

The food processing industries should come into play by providing more healthy balanced diets with specific functional attributes for the specific population like by promoting low trans fatty acid foods, zero cholesterol foods, high dietary fiber foods, low salt foods; etc. at an affordable price tag. Designed foods aimed for target groups like teenagers and adolescents can also be developed and marketed.

There are some herbal and medicinal plants that are reported to possess appetite suppressing activity that can play pivotal role in obesity and weight management. These are Caralluma fimbriata, Hoodia gordonii, Camellia sinensis (Green Tea), Capsicum annuum (Sweet/Bell Pepper), Psyllium/Plantain Fiber, Saffron Extract, XanoLean, Flaxseeds, Ginger, Umeboshi Plums, Almonds, Ilex paraguariensis (Yerba Mate), Chromium Chelate, Caffeine, Hydroxycitric Acid (HCA), Garcinia cambogia, Aloe vera juice, Bee Pollen, Evening Primrose Oil and Pineapple.

The information on the appetite suppressing plants and their potential in treatment of obesity and weight management is currently not available in a concise form. Thus this article focusses on the various medicinal plants and their bioactive constituents that can be used to suppress the appetite and can indirectly be successfully used in combating obesity.

\section{Caralluma fimbriata}

Caralluma fimbriata is a succulent plant, in the cactus family, that has been used as a natural appetite suppressant in India for centuries. The plant is becoming increasingly popular for their appetite suppressant and weight loss properties, as well as their ability to lower blood sugar. ${ }^{5,6}$

Caralluma fimbriata grows wild over various parts of India and has been used to suppress appetite and as a portable food for hunting. It is used to suppress hunger and appetite, and enhance endurance. It is also sometimes considered a "famine food," used during periods of famine to suppress appetite. It is also cooked as a vegetable, used in preserves like chutneys and pickles, or eaten raw.

Though very little scientific studies have been carried out on their mode of action it is believed to block the activity of several enzymes, 
which then blocks the formation of fat, forcing fat reserves to be burned. ${ }^{5}$ Caralluma fimbriata is also believed to have an effect on the appetite control mechanism of the brain.

The main bioactive phytochemicals present in its fruit are glycoside pregnane, flavone glycosides and megastigmane glycosides. These phytochemicals act by tricking the brain and signaling the body including the stomach to give the feeling of fullness. They also assist the body to absorb both the carbohydrates and fats and accelerate the use of fats in comparison to carbohydrates to generate energy in the body. However studies have shown that this plant is not a stimulant and does not affect the central nervous system.

Ayurvedic experts in traditional Indian medicine have noted that there are no adverse effects when using Caralluma fimbriata and the plant has no known toxicity till date.

However, a tested extract of Caralluma fimbriata has been developed, standardized and patented by a company called Gencor, California, USA. It is available under name as "Slimaluma," that delivers the concentrated form of the plant extract.

There is only one US based company that uses 'Slimaluma formula' which combines the patented Slimaluma extract of Caralluma fimbriata with EGCG (Epigallocatechin gallate) from green tea and market under the trade name Country Life's Gena Slim supplement. ${ }^{6}$

Studies have shown that together they show a synergistic effect on appetite control and weight loss and are also effective in reducing body fat.

\section{Hoodia gordonii}

Hoodia gordonii is a desert-originating, succulent, slow growing plant quite similar in appearance to cactus. ${ }^{7}$ It belongs to the order Gentianales of family Apocynaceae and sub-family Asclepiadaceae. It is widely distributed in Kalahari Desert of South Africa and is a member of milkweed family. Its usage as a plant in suppressing hunger dates back to centuries when San Bushman successfully used Hoodia to combat hungerduring his long hunting trips through the sweltering desert. However, there is still no sufficient scientific validation to depict its mode of action in suppressing hunger. It is believed that the active phytoconstituents are present in the plant sap that kills hunger. They are chemically a steroidal glycoside called P57 (14-OH, 12-tigloylpregnane) with mol. wt. $1008 .^{8,9}$ Its core steroid resembles with other cardenolides and its 14 -glucoside is similar to the one present in other species of Hoordia such as H. currori, H. macranth, H. parviflora, H. pilifera and H. Ruschii. ${ }^{10-12}$

Besides, 10 more new $\mathrm{C}(21)$-steroid derivatives called gordonii sides, have also been isolated from chloroform extracts of aerial $H$. gordonii. The new compounds are based on 3-beta, 14-beta-hydroxypregn-5-en-17-22 beta Ona. ${ }^{13}$

The mode of action of P57 is by reducing gastric acid secretion thereby combating hunger. Thus it can also be used in medications designed for treatment of gastric acid secretion disorders. ${ }^{14}$

However, contrary to this a research on broiler chickens showed that when their diet was supplemented with powdered $H$. gordonii at concentrations $0-500 \mathrm{mg} /$ animal/day showed no change in food consumption in animals during 30 days of experiment. ${ }^{15}$

In yet another study by Holt ${ }^{16}$ it was shown that formulations containing $H$. gordonii and other herbal medicines are able to suppress appetite and control obesity along with the treatment of other associated metabolic disorders. This statement is supported further as already discussed that the San people used $H$. gordonii for suppressing their hunger and thirst. ${ }^{17}$

However, further clinical trials are still needed to prove its role in hunger suppression and its potential in maintaining human health as no such scientific validation has been carried out till date. ${ }^{18}$ These products are quite popular in US and Europe and marketed as 'Hoodia max' supplement. This product claims to reduce around 1-6 pounds of weight perweek.

\section{Garcinia cambogia and Hydroxycitric acid (HCA)}

Garcinia cambogia is a closely related species of Garcinia also known as Guttiferae. This plant is native to Indonesia. The fruit of Garcinia cambogia looks like a small yellowish or reddish pumpkin with a thin skin and deep vertical lobes (resembles like orange). Their rinds are dried and cured during preparation for storage and processing for extraction. They are dark brown in colour.

Garcinia cambogia is also known as "Goroka" or "Kachampuli" (souring fruit) in the Western coastal areas of South India. It is used commercially in fish curing, in Sri Lanka it is also known as Colombo curing and other species of Garcinia are used in different food preparations in Thailand, Malaysia and Burma. The rind of the ripe fruit is acidic and is commonly consumed dried and used as a condiment in curries. ${ }^{19,20}$ The dietary supplements of "Garcinia" usually contain extracts of the dried rind of the fruit of this plant. The compound hydroxy-citric acid (HCA) is a key active Garcinia component that possesses biological activity. It naturally comprises up to $30 \%$ of the weight of the dried rind and around $50-60 \%$ of the weight of extracts is made from the dried rind. Only this particular species of Garcinia contains hydroxy-citric acid (HCA).

The primary role of adding Garcinia cambogia is to make meals 'more filling' besides its basic use in enhancing flavors in different food preparations and preservation. The extracts are also used as purgatives in the treatment of intestinal worms and other parasites, for tumors, dysentery and in the treatment of bilious digestive conditions.

HCA is amongst potent weight-loss options and is mainly found in the rind of Garcinia cambogia up to the level of $10-30 \%$ of dried rind. It can also be extracted from the other plants such as Malabar Tamarind that has a small sweet fruit and is also known as Mango steen or Garcinia cambogia. The mode of action is primarily through stimulating the metabolism that results in fat loss and ultimately weight loss. HCA also inhibits an enzyme ATP citrate lyase that blocks the conversion of ingested carbohydrates into fats in the body. Thus the blocked carbohydrates are diverted into energy production instead of storage as fat. Furthermore, the stored fatty acids are also utilized for energy production. This results in the shrinkage of overall body's fat.

Another closely related species is Garcinia mango steen that is specially cultivated for its fruit. However it lacks hydroxy citric acid (HCA). Garcinia species belongs to Southeast Asia growing wild though they are also cultivated in other areas as well. Thus there are 2 major benefits from HCA, i.e. it increases the levels of satiety thereby feeling less hunger and also reduces the number of calories stored as fat. ${ }^{21}$ In order to be effective, the HCA in Garcinia extract should be available to the body in sufficient amounts, should be obtained from good quality of Garcinia, and should be present in proper dose. There are two forms of HCA: the active HCA (free and unstable form) and 
the inactive HCA, the more stable (HCA lactone). The active form has a tendency to revert to the more stable (the inactive) form. Moreover, Garcinia extract has a tendency to become unstable through lactone formation as time passes.

However, some studies have also shown that Garcinia cambogia failed to produce significant weight loss and fat mass loss as observed with placebo.

\section{Yerba mate (Ilex paraguariensis)}

Yerba Mate or commonly called Mate is a type of herbal tea beverage that is prepared from an infusion of the dried leaves of Ilex paraguariensis (family Aquifoliaceae). ${ }^{22,23}$ It is widely consumed in southern Latin American countries including southern Brazil, Argentina, Paraguay, and Uruguay.

As per the scientific literature, Mate tea is hypo-cholesterolemic, hepato-protective, ${ }^{24}$ central nervous system-stimulating, diuretic, ${ }^{25}$ and antioxidant. ${ }^{26,27}$ It also provides protection to the cardiovascular system, ${ }^{28}$ DNA oxidation and low-density lipoprotein (LDL) lipoper oxidation under in vitro conditions. ${ }^{29}$

Research has shown that Mate tea can also be used in the management of obesity. ${ }^{30-32}$ There are various bioactive phytoconstituents present in Mate tea that contribute to its health benefits. The major phytochemicals are mainly the polyphenol like chlorogenic acid; xanthines like caffeine and theobromine; purine alkaloids like caffeic acid, 3, 4-dicaffeoylquinic acid, 3, 5-dicaffeoylquinic acid; flavonoids like quercetin, kaempferol, and rutin; some amino acids, minerals like Phosphorus, Iron, and Calcium and vitamins like B1, B2 and C. ${ }^{33,34}$

Mate tea contains high concentration of these bioactive phytochemicals. They show cytotoxic activity against human cancer hepatoma cells (HepG2). They also act as a catalytic inhibitor of topoisomerase II. ${ }^{35}$

Contrary to these findings, some studies have even reported that Mate tea increases the risk of various types of cancer like oral, oropharyngeal, esophageal, laryngeal, and bladder. ${ }^{36-38}$

The leaves of Yerba Mate are consumed as both hot and cold beverages. The Mate tea is diuretic, kills appetite, boost metabolism and reduces fatigue. The caffeine present in yerba mate acts as a stimulant and helps to burn body fat.

\section{Chromium chelate}

Chromium Chelate is a type of trace elements that has various health benefits. The mineral aids in fat metabolism, glucose regulation, insulin utilization and appetite suppression. The properties of chromium are such that it allows the body to work more efficiently in burning fat and utilizing sugar for energy. Chromium is present in very minute amounts in some foods, and therefore its dietary supplementation is necessary. ${ }^{39}$ Chromium affects the function of insulin in the body and helps to balance blood sugar level, controls appetite and increases metabolism.

Chromium is also utilized by the body in the form of chromium picolinate. It optimizes insulin function; thus maintains blood glucose levels that are normally responsible for carbohydrate cravings. Similar results have also been observed in preclinical trial studies. The mineral form of chromium has been shown to reduce carbohydrate cravings in a double-blind, placebo controlled study. ${ }^{40}$

\section{Caffeine}

Coffee is the most popular beverage throughout the world and has many health benefits. The bioactive phytoconstituents are mainly caffeine and chlorogenic acid that have appetite suppressing property by influencing energy expenditure and energy intake.

Contrary to this, a research reported that there is no significant effect of decaffeinated coffee, caffeine and their combinations on appetite sensation, energy intake, gastric emptying and plasma glucose levels. Thus the effect of caffeine and coffee for regulation of energy balance needs further study and experimental trials. ${ }^{41}$ In another study the effects of caffeine, caffeinated coffee, and decaffeinated coffee, both alone and in combination with $75 \mathrm{~g}$ of glucose, was assessed on perceived hunger and satiety and related peptides. The study showed that decaffeinated coffee can acutely decrease hunger and increase the satiety hormone PYY. ${ }^{42}$

However the long term human intervention studies have failed to prove the effects of caffeine and coffee consumption on the body weight. ${ }^{43,44}$ It might be due to the development of a tolerance to its effects. $^{43}$

Other controlled experiments investigating the effect of caffeine on calorie intake have found that caffeine has a small reducing effect on appetite suppression and calorie intake. ${ }^{45}$ These results were synonymous with the findings that restart of caffeinated coffee in consumers after a time gap reduced their frequency of meals without affecting meal size. This indirectly reduced their energy intake (EI). ${ }^{46}$ It was also found that increase in intake of caffeinated coffee resulted in smaller weight gain in men and women in comparison to controls. ${ }^{47}$

The other mode of action of caffeine is through thermogenic and lipolytic effect in the body. ${ }^{48}$ Caffeine functions through central and peripheral mechanisms that result in weight loss.

\section{Korean pine nut oil}

Korean pine (Pinus koraiensis) is native to eastern Asia including Korea, Manchuria, Mongolia, Temperate rainforests of the Russian Far East, and central Japan. The pine nut oil is obtained by natural pressing of Korean pine nuts. It contains triglycerides and more than $92 \%$ poly- and mono-unsaturated fatty acids (PUFAs and MUFAs) like pinolenic acid, linoleic acid and oleic acid. Its oil is unique as it contains about $15 \%$ pinolenic acid (C18:3). ${ }^{49}$

The free fatty acids present in the pine nut increases the release of satiety hormones such as cholecystokinin (CCK) that delays gastric emptying and produces an increased feeling of satiety and a decreased appetite..$^{50}$ It has also been reported that long chain fatty acids are more effective than medium chain fatty acids and PUFAs are more effective than MUFAs in terms of inducing satiety-hormone secretion. ${ }^{51}$

In another study, the free fatty acids of pine nut oil were administered to a group of obese postmenopausal women. The effect was a significant increase in CCK-8 and glucagon-like peptide-1 (GLP-1). The appetite sensation" prospective food intake" and "desire to eat" were lowered up to 4hours. ${ }^{50,52}$ Furthermore, the administration of Korean pine nut FFA at the rate of $2 \mathrm{~g}$ reduced lunch ad-libitum food intake by up to $9 \%$ compared with the placebo control. This was achieved without increasing caloric intake during the evening meal which suggests there is no compensation for the lesser food intake during lunch. ${ }^{53}$ So far till date no adverse effect of the compound has been reported. 


\section{Olibra (Palm oil and oat oil fractions)}

Olibra $\AA$ is a trade name of a fat emulsion that is made from palm oil (40\%) and oat oil fractions (2.5\%). Their mode of action is similar to that of Korean pine nut oil. It increases and prolongs the release of peptide YY, CCK and GLP-1 that further inhibits motility of the upper gut. This ultimately slows down gastric emptying and intestinal transit thereby generating an indirect satiety effect. ${ }^{43}$

In a study, it was found that administration of Olibra ${ }^{\circledR}$ to both lean, overweight and obese individuals significantly reduced hunger and desire to eat ${ }^{54}$ with a subsequent decrease of energy and macronutrient intake. This effect was sustained up to $36 \mathrm{~h}$ post-consumption of meal..$^{55}$ Thus the above results obtained with chronic administration suggest that Olibra ${ }^{\circledR}$ is effective in maintaining weight and can be successfully used in weight loss programs. ${ }^{43}$

\section{Tea catechins}

There are three types of tea that are widely used as health drinks throughout the world. They are oolong, green, and black tea. In addition, green tea and oolong tea also possess anti-obesity and hypolipidemic property.

\section{Oolong tea}

The main bioactive phytochemical in oolong tea are the Catechins that prevent obesity by two mechanisms; firstly they inhibit the formation of small-intestinal micelle and secondly they cause the inhibition of $\alpha$-glucosidase activity which leads to a decrease in carbohydrate absorption.

This has also been proved in a double-blind, placebo-controlled study where twelveweeks daily administration of oolong tea (containing 690mg of catechins) to normal and overweight males with daily energy intake set at $90 \%$ of recommended caloric intake produced a significant reduction in body weight of up to $1.5 \%$, body mass index (BMI) up to $1.5 \%$, waist circumference up to $2.0 \%$ and body fat mass up to $3.7 \%$ as compared to the placebo group. ${ }^{56}$ These studies clearly indicate that oolong tea consumption can be used as an adjuvant during weight loss programs.

\section{Green tea}

Green tea (Camellia sinensis) and its extract are well known for its anti-ageing and weight loss property. The mode of action of green tea in weight loss is through a thermogenic mechanism. ${ }^{57}$ The results are better when the tea is consumed regularly. The health benefits of green tea are due to the presence of bioactive phytochemical mainly Catechins like epigallocatechin-3-gallate (EGCG), epigallocatechin (EGC), epicatechin gallate (ECG) and epicatechin (EC).58

The daily intake of green tea in humans resulted in a decrease in body weight up to $0.6-1.25 \mathrm{~kg}$ and body fat by up to $0.5-1.8 \mathrm{~kg} .{ }^{59}$ However, it is important to highlight that in these studies participants were also subjected to moderate energy restriction ( $90 \%$ of individual energy requirements $)^{60}$ and exercise.$^{59}$ In yet another study it was found that administration of green tea to overweight participants produced a $4.6 \%$ decrease in body weight compared to baseline. ${ }^{61}$ Thermogenesis and fat oxidation are the main mechanisms responsible for weight loss. ${ }^{62}$ Studies have shown that Catechins present in green tea results in an increase in sympathetic nervous system activity, Thermogenesis and fat oxidation in humans. ${ }^{56}$

\section{Green coffee bean}

The main active phytochemicals present in green coffee bean extract (GCBE) are caffeine (10\%) and chlorogenic acid (27\%). However, the roasting process of coffee drastically reduces the level of chlorogenic acid and its related compounds. ${ }^{63}$ It has also been found in a study that when instant coffee enriched with chlorogenic acid was administered to humans, it induced a reduction in body fat and body mass in part due to a reduction in the absorption of glucose. The reduction of glucose absorption results in an increase in the consumption of fat reserves. This is due to the reduced availability of glucose as an energy source. ${ }^{64}$

\section{Citrus aurantium}

Citrus aurantium contains alkaloids such as $p$-octopamine and synephrines as the primary bioactive phytoconstituents which exhibit adrenergic agonist activity. ${ }^{65}$ They are thus used in dietary supplements for weight loss. ${ }^{66}$ The phytochemical synephrine increases energy expenditure (EE) and decrease food intake. ${ }^{67}$ In addition, studies have also shown that synephrines also decrease gastric motility.

There are a few trials that have examined the effects of $C$. aurantium synephrines alone and in combination with other ingredients, on various parameters like body weight and/or body composition in humans. Overall, these studies reported a loss of 2.4$3.4 \mathrm{~kg}$ among participants using synephrines, while placebo groups lost $0.94-2.05 \mathrm{~kg} .{ }^{68}$ These results indicates the potential of synephrines supplementation in weight loss therapy, however studies are still limited to separate the effects of C. aurantium or synephrines from those of other ingredients, in particular ephedrine.

\section{Catha edulis (Khat)}

The khat plant (Catha edulis) is a well-known appetite suppressant. The predominant bioactive phytochemical present in leaves of $C$. edulis is cathinone (1- $\alpha$-aminopropiophenone) and cathine (D-norpseudoephedrine) that is released on chewing. These compounds are similar to amphetamine and up to $90 \%$ is absorbed during chewing, predominantly through the oral mucosa. ${ }^{69}$ Amphetamine-like compounds affect the appetite centrally by acting in the hypothalamus. Besides its central effect, cathinone enhances sympathomimetic activity that leads to a delay in gastric emptying. In a study on healthy volunteers, it was observed that khat chewing decreased hunger and increased fullness scores. This was associated to a prolonged gastric emptying which was significant when compared to lettuce chewing. ${ }^{70}$

\section{Coleus forskohlii}

Coleus for skohlii is a plant rich in alkaloids that belongs to the mint family. The main bioactive phytochemical is forskolin, a diterpene, that acts directly on adenylate cyclase. Adenylate cyclase is an enzyme that activates cyclic adenosine monophosphate (cAMP). In turn cAMP promotes lipolysis, increases the body's basal metabolic rate, and increases utilization of body fat. In a study, administration of C. Forskohlii extract to overweight women mitigated weight gain with no significant side effects; however, weight loss was not achieved. Since this preparation affected weight gain further clinical study of C. Forskohlii is needed. ${ }^{71}$

Some other examples of natural good appetite suppressors are discussed briefly below. 


\section{Saffron extract}

Saffron is a natural spice and is commonly used for seasoning, fragrance. Its extract is used as a medicine as an appetite suppressant. In a study, all the women supplemented with saffron extract reported decreased hunger. The recommended dose was $88-90 \mathrm{mg}$ twice a day. However, not much literature and scientific data is available about the mode of action of saffron as appetite killer. The saffron extract has potential to be used as appetite suppressant or killer.

\section{Umeboshi plums}

Umeboshi Plums also known as Japanese salt plums are one of the best fruits available for weight loss. Plums can either be consumed fresh or dried; when dried they are known as prunes. But both the forms contain the same appetite suppressant properties. Studies indicate that a one-cup serving of pitted prunes contains 144 grams of water (another natural appetite suppressant). This accounts for nine percent of the daily recommended amount. Umeboshi plums are actually the pickled plums. The sourness of this fruit helps to decrease sugar cravings. They are very popular in Asian culture and have been named as an ultimate 'contractive food'.

\section{Xanolean}

XanoLean is a natural, nutrient-rich, botanical formula that works as a powerful appetite suppressant and produces a completely satisfied feeling while eating less food. The other advantage is that it has no side effects that are usually associated with many other weight loss products. XanoLean is actually marketed as the world's first nutraceutical formula to solve the problem of food addiction and breaking the cycle of compulsive overeating.

\section{Flaxseeds}

Flaxseeds are derived from the plant Linum usitatissimum. It is a powerful natural appetite suppressant. Flaxseeds support weight loss and are also a good source of dietary fiber and omega- 3 fatty acids. They can be sprinkled on yogurt or cottage cheese for a delicious, healthy snack. However, use of excessive flaxseed ingestion can increase bowel movements and cause gas and abdominal pain. The other uses of flax seeds are in the treatment of constipation, colon disorders, irritable colon, as a demulcent in gastritis and enteritis.

\section{Ginger (Zingiber officinale)}

Ginger has been consumed by the humans for its health benefitting properties since times immemorial. Ginger is highly digestive and works as a stimulant to energize the body and improve digestion thus feeling less hungry. Overall ginger is a natural and inexpensive appetite suppressant.

\section{5-Hydroxytryptophan (5-HTP)}

5-hydroxy tryptophan (5-HTP) is a naturally-occurring amino acid precursor to serotonin. There are numerous studies including those randomized, double-blind and placebo-controlled that has confirmed the safety and efficacy of 5-HTP in reducing appetite and food intake in both the obese and healthy and non-insulin-dependent diabetic individuals.

A 2006 study in mice concluded that 5-HTP-induced anorexia may be mediated by facilitation of leptin secretion. Vitamins B6 and C are important co-factors in the 5-HTP to serotonin pathway. Amongst the several serotonin receptors thus identified, the $5 \mathrm{HT} 2 \mathrm{C}$ receptors are involved in control of food intake. Mice without this receptor exhibit increased food intake and become obese. ${ }^{73}$

A follow-up study compared 5-HTP to placebo during a diet and non-diet period and found that those who took 5-HTP lost about $2 \%$ of their body weight during the non-diet period and another 3\% when they dieted. However, those taking placebo did not lose any weight. ${ }^{74}$

\section{DL-phenylalanine (DLPA)}

DLPA is a combination of the $\mathrm{d}$ - and the 1 - forms of phenylalanine, an essential amino acid. Phenylalanine suppresses appetite by regulating the release of cholecystokinin (an appetite suppressing hormone), which in turns signals satiety in the brain. D-phenylalanine increases endorphins, while L-phenylalanine is an amphetamine like stimulatory compound. DLPA elevates mood, curb appetite and reduces pain.

The amino acid phenylalanine is found in a variety of foods including almonds, avocados, bananas, brown rice, cheese, corn, eggs, fish, lima beans, peanuts, pumpkin seeds, sesame seeds and soy products.

The role of cholecystokinin in appetite suppression was also proven in a lab study on rhesus monkeys. In the first test, monkeys were given cholecystokinin intravenously after having been deprived of food overnight. The monkey's appetites were suppressed. In the second test, the monkeys were fasted during the previous test night. The monkeys felt hungry and were given phenylalanine to suppress their appetite. The test thus indicated that phenylalanine helps to release cholecystokinin, the hormone that suppresses appetite. ${ }^{75}$ Thus DLPA can be used as dietary supplements for appetite suppression.

\section{L-Tyrosine}

L-Tyrosine is an essential amino acid and chemically known as 4-hydroxyphenylalanine. It is produced from phenylalanine, an essential amino acid. Upon production, tyrosine can be used to synthesize a number of essential compounds in the body. Tyrosine is used as a mood elevator, to increase alertness after sleep deprivation and as an appetite suppressant; although support for the latter appears anecdotal..$^{72}$

L-Tyrosine is required for conversion into the catecholamine neurotransmitters stress depletes such as dopamine, nor epinephrine and epinephrine. It is also a precursor for thyroxine.

There are only a very few scientific studies done on the association between L-tyrosine and weight loss. Mostly, these studies involve only tyrosine when taken alongside other weight loss supplements.

In a study, a combination of caffeine, capsaicin, catechins and tyrosine was trialed as a weight loss combination in a group of obese patients. It is believed that the bioactive food supplements assembled in the combination are known to induce thermogenesis, promote satiety and lipolysis. This is due to the stimulation of the sympathetic nervous system.

In a study, 80 obese subjects were recruited who were placed on a low calorie diet for 4 weeks.

Those who lost more than $4 \%$ of their body weight after the fourth week were placed on the combination of bioactive food supplements or placebo for 8 weeks. The subjects were tested before and after the 
8 week period. Among the factors measured were blood pressure, heart rate and body weight. The results of the study showed that the bioactive supplement including tyrosine increased thermogenesis. While all the subjects experienced significant weight loss after the 4weeks on which they were placed on the weight loss diet, those who received the tyrosine-containing supplement experienced even greater reduction in body fat mass. This reduction was not as significant as the one caused by the low calorie diet, however, it was enough to help maintain the weight loss produced by the restricted diet.

It is believed that L-Tyrosine promotes weight loss by alleviating stress and depression. Since L-tyrosine is used to produce neurotransmitters such as dopamine, it can help improve mood, manage depression and helps relieve stress.

Both stress and depression can cause periods of inactivity which may further promote weight gain. By improving the mood and reducing the production of stress hormones, tyrosine prevents weight gain and prompt weight loss by increasing the user's participation in daily activities.

Another mechanism of L-tyrosine in weight loss is by suppressing appetite. Different studies in animal models have shown that tyrosine can improve the appetite suppressant effects of supplements that stimulate the sympathetic nervous system. Such supplements include ephedra and therefore L-tyrosine is often included with ephedra and ephedra-containing herbs. However, only tyrosine does not suppress appetite.

Yet another beneficial effect of tyrosine is in stimulating the production of neuro-hormones such as epinephrine and nor epinephrine. This result in thermogenesis and the increased muscular activity caused by the increased production of these compounds that help burn stored fat.

L-tyrosine also functions by improving thyroid functioning. The thermogenic effects of L-tyrosine are also due to the increased thyroid hormone synthesis. Since tyrosine is a precursor used in the production of both triiodothyronine (T3) and thyroxine (T4); it is routinely used in the treatment of hypothyroidism. ${ }^{76}$ The thyroid hormones promote metabolism including the burning of stored fats and the immediate release of energy. Thus tyrosine promotes weight loss by improving thyroid functioning. ${ }^{77}$ For this reason, tyrosine is especially useful in the shedding of weight caused by low production of thyroid hormones.

\section{L-glutamine}

L-Glutamine is well known for gut and immune support. Recently studies have also its role in reducing carbohydrate cravings and support alcohol withdrawal. However, the mechanism of action for these benefits is still unknown. ${ }^{72}$

\section{Aloe vera juice}

Aloe juice enhances digestion, detoxifies the digestive tract naturally and develops a healthier and stable appetite and a glowing skin. The recommended dose is 4-8 ounces per day.

\section{Bee pollen}

Bee pollen suppresses appetite and energizes metabolism. However, some people are allergic to bee pollen and should be avoided. The mode of action of bee pollen in weight loss and as appetite suppressant is still unknown and more scientific studies are needed to support their role in weight control.

\section{Evening primrose oil}

Evening primrose is a well-known female tonic, and its extract contains tryptophan, which has been associated with weight loss. Likewise bee pollen, the mode of action of evening primrose oil in weight loss and as appetite suppressant is still unknown.

\section{Pineapple}

Bromelain is an enzyme found in pineapple juice and in the pineapple stem. Bromelain digests fats and proteins, creating smoother digestion and healthier appetite. However, bromelain has no established research evidence as a nutraceutical or drug.

\section{Psyllium seed/Plantain (Plantago ovata)}

The seeds of plantain are well known for their appetite suppressing effect. They also protect against heart disease and diabetes since they are rich in fibers. Overall they promote the feeling of fullness. In a study, it was shown that psyllium seeds helps to balance blood glucose levels and improves the absorption of insulin. Furthermore, psyllium seeds also help to reduce high cholesterol levels and high blood pressure.

\section{Sweet pepper (Capsicum annum)}

Sweet pepper also known as Bell Pepper also helps to kill appetite. They are the rich sources of antioxidants and vitamin C. They are also high in Bromelain acid. The characteristic aroma of green peppers is due to the presence of 3-isoButyl-2-methoxypyrazine (IBMP). In a study, the role of bioactive compounds present in capsaicin (an extract from hot chili peppers), green tea and sweet peppers was determined showing an increased feeling of satiety and fullness. In yet another study it was found that a combination of fiber, green tea compounds and caffeine was most effective in reducing hunger and increasing sensations of fullness.

\section{Conclusion and perspectives}

From the above findings it can be concluded that there are many appetite suppressing medicinal plants and their bioactive phytochemical constituents that can be used to control weight gain. Although these products being herbal are considered to be safe but some toxicity is also associated with them. Thus more research is needed in order to use these plant metabolites as anti-obesity agents and for weight control. Besides, more clinical trials are required to prove their non-toxic effects and to develop most effective combinations of the appetite killer plants since there is no single phyto nutrient or plant that is sufficient alone to control weight gain and obesity. At the outset, the future of the appetite suppressing plants holds great potential and promising.

\section{Acknowledgements}

None.

\section{Conflict of interest}

Author declares that there is no conflict of interest.

\section{References}
1. http://www.who.int/mediacentre/factsheets/fs311/en/
2. Kopelman PG. Obesity as a medical problem. Nature.
3. 2000;404(6778):635-643. 
4. Flier JS. Obesity wars: molecular progress confronts an expanding epidemic. Cell. 2004;116(2):337-350.

5. Friedman JM. A war on obesity, not the obese. Science. 2003;299(5608):856-858.

6. Khan B, Arayne MS, Naz S, et al. Hypogylcemic activity of aqueous extract of some indigenous plants. Pak J Pharm Sci. 2005;18(1):62-64.

7. Caralluma fimbriata: A new dietary supplement in weight management strategies. Report to the U.S. Food and Drug Administration.

8. Van Beek TA, Verpoorte R, Svendsen AB, et al. Tabernaemont (Apocynaceae): A review of its taxonomy, phytochemistry, ethnobotany and pharmacology. J Ethnopharmacol. 1984;10(1):1-156.

9. Bruyns PV. Stapeliads of Southern Africa and Madagascar. Umdaus Press; 2005;1:4-8.

10. MacLean DB, Luo LG. Increased ATP content/production in the hypothalamus may be a signal for energy-sensing of satiety: studies of the anorectic mechanism of a plant steroidal glycoside. Brain Res. 2004;1020(1-2):1-11.

11. Avula B, Wang YH, Pawar RS, et al. Chemical fingerprinting of Hoodiaspecies and related genera: chemical analysis of oxypregnane glycosides using high-performance liquid chromatography with UV detection in Hoodia gordonii. J AOAC Int. 2007;90(6):1526-1531.

12. Avula B, Wang Y, Pawar RS, et al. A rapid method for chemical fingerprint analysis of Hoodiaspecies, related genera and dietary supplements using UPLC-UV-MS. J Pharm Biomed Anal. 2008;48(3):722-731.

13. Van Heerden FR, Horak RM, Maharaj VJ, et al. An appetite suppressant from Hoodia species. Phytochemistry. 2007;68(20):2545-2553.

14. Dall'Acqua S, Innocenti G. Steroidal glycosides from Hoodia gordonii. Steroids. 2007;72(6-7):559-568.

15. https://www.google.co.in/patents/n\&sa=X\&ved=0ahUKEwj414mv6O7J AhWXBY4KHcqhC3EQ6AEIIzAB

16. Mohlapo TD, Ng 'ambi JW, Norris D, et al. Effect of Hoodiagordoniimea supplementation at finisher stage on productivity and carcass characteristics of Ross 308 broiler chickens. Tropical Animal Health and Production. 2009;41(7):1591-1596.

17. Holt S. Herbal compositions containing Hoodia. United States; 2006:WO2006079055A1

18. World Health Organization -WHO. Access to AIDS medicines stumbles on trade rules. Bulletin of the World Health Organization. 2006;84(5):342-348

19. Pereira CA, Pereira LLS, Corrêa AD. Hoodia gordoniiin the treatment of obesity: A review. Journal of Medicinal Plants Research. 2010;4(22):2305-2312.

20. Clouatre D, Rosenbaum ME. The Diet and Health Benefits of HCA (Hydroxycitric Acid); New Canaan, CT: Keats Publishing Inc. Appendix s Many observational studies in addition to the above indicate that Garcinia Cambogia has a long histon, j of use as a food. 1994.

21. Drury H. The Useful Plants of India. 2nd ed. London: William H Allen \& Co; 1873. 220p

22. Harry GP, Dallas C. Garcinia Cambogia: How to Optimize Effects. 2013

23. Small E, Catling PM. Blossoming treasures of biodiversity: Mate (Ilex paraguariensis) - better than Viagra, marijuana, and coffee? Biodiversity. 2001;2:26-27.

24. Grigioni G, Carduza F, Irurueta M, et al. Flavour characteristics of Ilex paraguariensisinfusion, a typical Argentine product, assessed by sensory evaluation and electronic nose. Journal of the Science of Food and Agriculture. 2004;84(5):427-432.
25. Filip R, Ferraro GE. Researching on new species of Mate: Ilex brevicuspis: phytochemical and pharmacology study. Eur J Nutr. 2003;42(1):50-54

26. Gonzalez A, Ferreira F, Vazquez A, et al. Biological screening of Uruguayan medicinal-plants. J Ethnopharmacol. 1993;39(3):217-220.

27. Filip R, Lotito SB, Ferraro G, et al. Antioxidant activity of Ilex paraguariensis and related species. Nutrition Research. 2000;20(10):1437-1446.

28. VanderJagt TJ, Ghattas R, VanderJagt DJ, et al. Comparison of the total antioxidant content of 30 widely used medicinal plants of New Mexico. Life Sci. 2002;70(9):1035-1040.

29. Schinella G, Fantinelli JC, Mosca SM. Cardioprotective effects of Ilex paraguariensis extract: evidence for a nitric oxide-dependent mechanism. Clin Nutr. 2005;24(3):360-366.

30. Bracesco N, Dell M, Rocha A, et al. Antioxidant activity of a botanical extract preparation of Ilex paraguariensis: prevention of DNA doublestrand breaks in Saccharomyces cerevisiae and human low-density lipoprotein oxidation. J Altern Complement Med. 2003;9(3):379-387.

31. Andersen T, Fogh J. Weight loss and delayed gastric emptying following a South American herbal preparation in overweight patients. J Hum Nutr Diet. 2001;14(3):243-250.

32. Pittler MH, Ernst E. Dietary supplements for body-weight reduction: a systematic review. Am J Clin Nutr. 2004;79(4):529-536.

33. Opala T, Rzymskip P, Pischel I, et al. Efficacy of 12 weeks supplementation of a botanical extract-based weight loss formula on body weight, body composition and blood chemistry in healthy, overweight subjects - a randomized double-blind placebo-controlled clinical trial. Eur J Med Res. 2006;11(8):343-350.

34. Pomilio AB, Trajtemberg S, Vitale AA. High-performance capillary electrophoresis analysis of Mate infusions prepared from stems and leaves of Ilex paraguariensis using automated micellar electro kinetic capillary chromatography. Phytochem Anal. 2002;13(4):235-241.

35. Zaporozhets OA, Krushynska OA, Lipkovska NA, et al. A new test method for the evaluation of total antioxidant activity of herbal products. J Agric Food Chem. 2004;52(1):21-25.

36. Ramirez-Mares MV, Chandra S, deMejia EG. In vitro chemo preventive activity of Camellia sinensis, Ilex paraguariensis and Ardisiacompressa tea extracts and selected polyphenols. Mutat Res. 2004;554(1-2): 53-65.

37. Goldenberg D, Golz A, Joachims HZ. The beverage Mate: a risk factor for cancer of the head and neck. Head Neck. 2003;25(7):595-601.

38. Sewram V, De Stefani E, Brennan P, et al. Mate consumption and the risk of squamous cell esophageal cancer in Uruguay. Cancer Epidemiol Biomarkers Prev. 2003;12(6):508-513.

39. Bates MN, Hopenhayn C, Rey OA, et al. Bladder cancer and Mate consumption in Argentina: a case-control study. Cancer Lett. 2007;246(1-2):268-273.

40. Preuss Harry G, Anderson RA. Chromium update: examining recent literature 1997- 1998. Curr Opin Clin Nutr Metab Care. 1998;1(6):509-512.

41. Hallmark MA, Reynolds TH, DeSouza CA, et al. Effects of chromium and resistive training on muscle strength and body composition. Med Sci Sports Exerc. 1996;28(1):139-144.

42. Schubert MM, Grant G, Horner K, et al. Coffee for morning hunger pangs An examination of coffee and caffeine on appetite, gastric emptying, and energy intake. Appetite. 2014;83:317-326.

43. Greenberg JA, Geliebter A. Coffee, hunger, and peptide YY. J Am Coll Nutr. 2012;31(3):160-166. 
44. Diepvens K, Westerterp KR, Westerterp-Plantenga MS. Obesity and thermogenesis related to the consumption of caffeine, ephedrine, capsaicin, and green tea. Am J Physiol Regul Integr Comp Physiol. 2007;292(1):R77-R85.

45. Westerterp-Plantenga MS, Lejeune MP, Kovacs EM. Body weight loss and weight maintenance in relation to habitual caffeine intake and green tea supplementation. Obes Res. 2005;13(7):1195-1204.

46. Belza A, Toubro S, Astrup A. The effect of caffeine, green tea and tyrosine on thermogenesis and energy intake. Eur J Clin Nutr. 2009;63(1):57-64.

47. Jessen A, Buemann B, Toubro S, et al. The appetite-suppressant effect of nicotine is enhanced by caffeine. Diabetes Obes Metab. 2005;7(4):327-333.

48. Lopez-Garcia E, van Dam RM, Rajpathak S, et al. Changes in caffeine intake and long-term weight change in men and women. Am J Clin Nutr. 2006;83(3):674-680.

49. Graham TE. Caffeine and exercise: Metabolism, endurance and performance. Sports Med. 2001;31(11):785-807.

50. Alper CM, Mattes RD. Effects of chronic peanut consumption on energy balance and hedonics. Int $J$ Obes Relat Metab Disord. 2000;26(8):1129-1137.

51. Pasman WJ, Heimerikx J, Rubingh CM, et al. The effect of Korean pine nut oil on in vitroCCK release, on appetite sensations and on gut hormones in postmenopausal overweight women. Lipids Health Dis. 2008;7:10.

52. Lawton CL, Delargy HJ, Brockman J, et al. The degree of saturation of fatty acids influences post-ingestive satiety. Br J Nutr. 2000;83(5):473-482.

53. Scott C, Pasman W, Hiemerikx J, et al. Pinnothin ${ }^{\mathrm{TM}}$ suppresses appetite in overweight women. Appetite. 2007;49(1):330.

54. Hughes GM, Boyland EJ, Williams NJ, et al. The effect of Korean pine nut oil (PinnoThin) on food intake, feeding behaviour and appetite: a double-blind placebo-controlled trial. Lipids Health Dis. 2008;7:6.

55. Diepvens K, Steijns J, Zuurendonk P, et al. Short-term effects of a novel fat emulsion on appetite and food intake. Physiol Behav. 2008;95(1-2):114-117.

56. Burns AA, Livingstone MB, Welch RW, et al. Dose-response effects of a novel fat emulsion (Olibra) on energy and macronutrient intakes up to 36 h post consumption. Eur J Clin Nutr. 2002;56(4):368-377.

57. Nagao T, Komine $\mathrm{Y}$, Soga $\mathrm{S}$, et al. Ingestion of a tea rich in catechins leads to a reduction in body fat and malondialdehyde-modified LDL in men. Am J Clin Nutr. 2005;81(1):122-129.

58. Wolfram S, Wang Y, Thielecke F. Anti-obesity effects of green tea: From bedside to bench. Mol Nutr Food Res. 2006;50(2):176-187.

59. Mandel SA, Amit T, Weinreb O, et al. Simultaneous manipulation of multiple brain targets by green tea catechins: A potential neuroprotective strategy for Alzheimer and Parkinson diseases. CNS Neurosci Ther. 2008;14(4):352-365.

60. Maki KC, Reeves MS, Farmer M, et al. Green tea catechin consumption enhances exercise-induced abdominal fat loss in overweight and obese adults. J Nutr. 2009;139(2):264-270.
61. Diepvens K, Kovacs EM, Vogels N, et al. Metabolic effects of green tea and of phases of weight loss. Physiol Behav. 2006;87(1):185-191.

62. Chantre P, Lairon D. Recent findings of green tea extract AR25 (Exolise) and its activity for the treatment of obesity. Phytomedicine. 2002;9(1):3-8.

63. Rudelle S, Ferruzzi MG, Cristiani I, et al. Effect of a thermogenic beverage on 24hour energy metabolism in humans. Obesity (Silver Spring). 2007;15(2):349-355.

64. del Castillo MD, Ames JM, Gordon MH. Effect of roasting on the antioxidant activity of coffee brews. J Agric Food Chem. 2002;50(13):3698-3703.

65. Thom E. The effect of chlorogenic acid enriched coffee on glucose absorption in healthy volunteers and its effect on body mass when used long-term in overweight and obese people. $J$ Int Med Res. 2007;35(6):900-908.

66. Pellati F, Benvenuti S, Melegari M, et al. Determination of adrenergic agonists from extracts and herbal products of Citrus aurantium L. var. amara by LC. J Pharm Biomed Anal. 2002;29(6):1113-1119.

67. Preuss HG, DiFerdinando D, Bagchi M, et al. Citrus aurantium as a thermogenic, weight-reduction replacement for ephedra: An overview. $J$ Med. 2002;33(1-4):247-264.

68. Astrup A. Thermogenic drugs as a strategy for treatment of obesity. Endocrine. 2000;13(2):207-212.

69. Haaz S, Fontaine KR, Cutter G, et al. Citrus aurantium and synephrine alkaloids in the treatment of overweight and obesity: An update. Obes Rev. 2006;7(1):79-88.

70. Toennes SW, Harder S, Schramm M, et al. Pharmacokinetics of cathinone, cathine and nor-ephedrine after the chewing of khat leaves. $\mathrm{Br} \mathrm{J} \mathrm{Clin}$ Pharmacol. 2003;56:125-130.

71. Murray CD, Le Roux CW, Emmanuel AV, et al. The effect of Khat (Cathe edulis) as an appetite suppressant is independent of ghrelin and PYY secretion. Appetite. 2008;51(3):747-750.

72. Henderson S, Magu B, Rasmussen C, et al. Effects of Coleus forskohlii supplementation on body composition and hematological profiles in mildly overweight women. J Int Soc Sports Nutr. 2005;2:54-62.

73. http://www.ibtimes.com/saffron-extract-flaxseeds-5-other-naturalappetite-suppressants-419644

74. Ceci F, Cangiano C, Cairella $M$, et al. The effects of oral 5-hydroxytryptophan administration on feeding behavior in obese adult female subjects. J Neural Transm. 1989;76(2):109-117.

75. Cangiano C, Ceci F, Cascino A, et al. Eating behavior and adherence to dietary prescriptions in obese adult subjects treated with 5-hydroxytryptophan. Am J Clin Nutr. 1992;56(5):863-867.

76. http://www.smart-publications.com/articles/appetite-out-of-controlphenylalanine-may-be-the-answer

77. http://www.progressivehealth.com/1-tyrosine-for-weight-loss.htm

78. Mauro Di Pasquale. An In-Depth Analysis of L-Tyrosine. 2006. 